\title{
Joint factorial structure of psychopathology and personality
}

\section{Rosenström, Tom}

2019-10

Rosenström , T , Gjerde , L C , Krueger , R F , Aggen , S H , Czajkowski , N O , Gillespie , N A , Kendler , K S , Reichborn-Kjennerud, T , Torvik , F K \& Ystrom , E 2019 , ' Joint factorial structure of psychopathology and personality ' , Psychological Medicine , vol. 49 , no. 13 , 0033291718002982 , pp. 2158-2167 . https://doi.org/10.1017/S0033291718002982

http://hdl.handle.net/10138/311827

https://doi.org/10.1017/S0033291718002982

cc_by_nc_nd

acceptedVersion

Downloaded from Helda, University of Helsinki institutional repository.

This is an electronic reprint of the original article.

This reprint may differ from the original in pagination and typographic detail.

Please cite the original version. 
This Accepted Manuscript (AM) version for Psychological Medicine is subject to copyright regulations. Version of Record (VoR) to appear in https://www.cambridge.org/core/journals/psychological-medicine.

\section{Joint factorial structure of psychopathology and personality}

Tom Rosenström ${ }^{1,2, *}$, Line C. Gjerde ${ }^{1,3}$, Robert F. Krueger ${ }^{4}$, Steven H. Aggen ${ }^{5}$, Nikolai Olavi Czajkowski $^{1,3}$, Nathan A. Gillespie ${ }^{5}$, Kenneth S. Kendler ${ }^{5,6,7}$, Ted Reichborn-Kjennerud ${ }^{1,8}$, Fartein Ask Torvik ${ }^{1,3, \dagger}$, Eivind Ystrom ${ }^{1,3,8, \uparrow}$

${ }^{1}$ Department of Mental Disorders, Norwegian Institute of Public Health, Oslo, Norway;

${ }^{2}$ Department of Psychology and Logopedics, University of Helsinki, Finland;

${ }^{3}$ Department of Psychology, University of Oslo, Norway;

${ }^{4}$ Department of Psychology, University of Minnesota, USA;

${ }^{5}$ Department of Psychiatry, Virginia Institute for Psychiatric and Behavioral Genetics, Virginia Commonwealth University, Richmond, VA, USA;

${ }^{6}$ Deparment of Human and Molecular Genetics, Virginia Commonwealth University, Richmond, VA, USA;

${ }^{7}$ Department of Psychiatry, Virginia Commonwealth University, Richmond, VA, USA;

${ }^{8}$ Institute of Clinical Medicine, University of Oslo, Norway;

${ }^{8}$ PharmacoEpidemiology and Drug Safety Research Group, School of Pharmacy, University of Oslo, Norway;

*Correspondence to tom.rosenstrom@ @elsinki.fi; Folkehelseinstituttet, Postboks 4404, Nydalen, 0403 Oslo; Tel: 00358445397665

$\dagger$ †oint senior authors

Funding: We acknowledge funding from the US National Institutes of Health and National Institute on Drug Abuse (1R01DA037558-01A1), the Research Council of Norway (226985; 240061), the Norwegian Foundation for Health and Rehabilitation, the Norwegian Council for Mental Health, and the European Commission under the program "Quality of Life and Management of the Living Resources" of the Fifth Framework Program (QLG2-CT-2002-01254). 


\section{Abstract}

Background: Normative and pathological personality traits have rarely been integrated into a joint large-scale structural analysis with psychiatric disorders, although a recent study suggested they entail a common individual differences continuum.

Methods: We explored the joint factor structure of 11 psychiatric disorders, five personality-disorder trait domains (DSM-5 Section III), and five normative personality trait domains (the 'Big Five') in a population-based sample of 2796 Norwegian twins, aged 19-46.

Results: Three factors could be interpreted: (i) a general risk factor for all psychopathology, (ii) a risk factor specific to internalizing disorders and traits, and (iii) a risk factor specific to externalizing disorders and traits. Heritability estimates for the three risk factor scores were $48 \%(95 \% \mathrm{Cl}=41-$ $54 \%), 35 \%(\mathrm{Cl}=28-42 \%)$, and $37 \%(\mathrm{Cl}=31-44 \%)$, respectively. All 11 disorders had uniform loadings on the general factor (congruence coefficient of 0.991 with uniformity). Ignoring sign and excluding the Openness trait, this uniformity of factor loadings held for all the personality trait domains and all disorders (congruence 0.983).

Conclusions: Based on our findings, future research should investigate joint etiologic and transdiagnostic models for normative and pathological personality and other psychopathology. 


\section{Introduction}

Multiple psychiatric disorders often co-occur in the same individuals to the extent that different research programs have been developed to explain the comorbidity and to revise diagnostic systems (Cuthbert 2014; Del Giudice 2016; Borsboom 2017; Kotov et al. 2017). Personality has not been routinely integrated to these models, and for a long time, psychiatric nosology has separated personality (Axis II) disorders from other psychiatric (Axis I) disorders. However, relationships between personality and other psychiatric disorders have been studied much (Kotov et al. 2010), and a recent study suggested that normative and pathological personality as well as other psychiatric disorders "are likely to entail a common individual differences continuum" (Oltmanns et al. 2018). Here a joint factor model over personality and psychiatric domain constructs is explored in a representative and a genetically informative population sample - to our knowledge, for the first time.

Exploratory factor analysis seeks to explain correlations among multiple variables with a smaller number of underlying "factors" (Lawley \& Maxwell 1971). When fitted to data, the model may reveal a theoretically more informative account of the inter-dependencies between multiple variables. For a long time, different psychiatric disorders have been grouped into internalizing and externalizing disorder factors (also called spectra) to distinguish and characterize core processes contributing to psychiatric comorbidity (Achenbach 1966; Krueger 1999; Kotov et al. 2017).

More recently, researchers have increasingly payed attention to the substantial correlation between the internalizing and externalizing factors (Lahey et al. 2012; Kotov et al. 2017). On a practical level, the correlation between the internalizing and externalizing factors indicates that these broad dimensions are 'comorbid' with each other, and therefore may share and dilute underlying risk factors that would ideally be diagnostic targets. For these reasons, a general factor model has been proposed, which partitions psychiatric comorbidity to a "super-spectrum", or " $p$ 
factor", reflecting general overarching risk for all psychopathology, and two domain-specific 'residual' factors of internalization and externalization risk (Lahey et al. 2011, 2012; Caspi et al. 2014). The domain-specific factors are uncorrelated with the $p$ factor in this "bi-factor" model. Attempts to statistically demonstrate superiority of a given factor model compared to alternatives have run into difficulties due to possible use of too many factors (Hayashi et al. 2007; Eid et al. 2017), high 'fitting propensity' (Bonifay \& Cai 2017), and because attempts to confirm psychiatric disorders as pure 'measures' of an underlying factor may be unrealistic even if they would 'reflect' such factors (Asparouhov \& Muthén 2009). Exploratory factor modeling suffers less from these problems (Asparouhov \& Muthén 2009; Garrido et al. 2013), and in terms of fit, it expresses bi-factor and correlated-factor models as coequal rotations of the same statistical model (Jennrich \& Bentler 2011, 2012). From a substantive standpoint, the models have different implications, however, as will be further discussed below. Of note, we do not consider the "hierarchical" (a.k.a., "second-order") factor model that is not a rotation but a constrained (i.e., confirmatory) sub-model to the rotations studied herein, and potentially very difficult to distinguish from the bi-factor model (Mansolf \& Reise 2017; Caspi \& Moffitt 2018).

The previous research on bi-factor models have used limited personality data (e.g., antisocial personality disorder) (Lahey et al. 2012) and studied correlations between further personality traits and model-implied factors (Tackett et al. 2013; Caspi et al. 2014; Neumann et al. 2016), but they did not study more comprehensive trait systems as a possible part of the factorial structure, as suggested by Oltmanns et al. (2018). Here, we will do this and discuss the relative parsimony of the structures that the correlated-factor and bi-factor models suggest. Among quantitative models of personality, the system of "Big Five" traits has received most attention (John et al. 2008; Widiger \& Mullins-Sweatt 2009; Kotov et al. 2010). This system compares individuals on five normative dimensions: Extraversion, Agreeableness, Conscientiousness, Neuroticism, and Openness. Recently, another five-dimensional clinical version of the big-five personality system (assessing maladaptive variants) was introduced as an alternative to, and as a possible future 
replacement of, the existing DSM system of personality disorders (American Psychiatric Association 2013). Here, we use both the big five traits and a brief form for DSM-5 Section III personality trait model to cover both normative and pathological personality trait systems. The two systems cover partly non-overlapping personality aspects as the pathological trait system better captures genetic variance in DSM-IV personality disorders than the normative trait system (Reichborn-Kjennerud et al. 2017; Czajkowski et al. 2018).

In this study, we investigated (i) the minimum number of underlying factors that are needed to adequately account for the population correlations between variables for 11 commonly studied psychiatric disorders, five pathological personality traits, and five normative personality traits, (ii) what these factors look like from correlated-factor versus bi-factor perspectives, and (iii) what their heritability and genetic correlations are. We also (iv) address possible response style effects on factor structure, which have been frequently discussed in context of the $p$ factor (e.g., Neumann et al. 2016; Caspi \& Moffitt 2018; Oltmanns et al. 2018); namely, we controlled for extreme and acquiescent self-reporting styles (Weijters et al. 2010a, 2010b; Wetzel et al. 2016) because they would have given rise to an apparent methods factor without obvious substantive interpretation. The personality research field has favored the dimensional trait systems because there has been little or no evidence supporting a typological organization of personality (Markon et al. 2011; Haslam et al. 2012; Rosenström \& Jokela 2017), and the recently suggested DSM pathological personality trait system appears to capture all the genetic and most of the environmental variance in the older typological system of personality disorders (ReichbornKjennerud et al. 2017). For these reasons and for the sake of concise exposition and computational feasibility, we did not include older personality disorder systems, with the exception of antisocial personality disorder that has typically been included in studies of $p$ factor in one form or another (e.g., conduct disorder has been used in studies on children, and registered crimes have been used in registry studies) (Lahey et al. 2011, 2012; Caspi et al. 2014; Neumann et al. 2016; Pettersson et al. 2016; Waldman et al. 2016). 


\section{Methods and Materials}

\section{Sample}

Data for these analyses came from a population-based sample of Norwegian twins recruited from the Norwegian Institute of Public Health Twin Panel (Nilsen et al. 2013). Approval for this study was received from The Norwegian Data Inspectorate and the Regional Committee for Medical and Health Research Ethics, and written informed consent was obtained from all participants after a complete description of the study. In wave 1 data, collected between the years 1999 and 2004, lifetime history of major DSM-IV Axis I disorders and all the 10 Axis II personality disorders in the past 5 years were assessed at interview in 2801 twins (43.5\% of those who were eligible; 1390 complete twin pairs and 21 single twins; average age 28.2 years, age range 19-36). Despite moderate selection towards good mental and somatic health, attrition did not appear to affect twin analyses of mental health according to an attrition study (Tambs et al. 2009). In wave 2, altogether 2284 twins (987 complete pairs and 310 single twins) were re-interviewed approximately 10 years later, and they filled in a mailed self-report questionnaire for personality. Attrition from $1^{\text {st }}$ to $2^{\text {nd }}$ wave was low $(82.2 \%$ were retained).

\section{Measures}

At both waves, lifetime psychiatric disorders were assessed using computerized Norwegian version of the World Health Organization's Composite International Diagnostic Interview (CIDI) (Wittchen \& Pfister 1997). Criteria for antisocial personality disorder within the past 5 years were assessed using a Norwegian version of the Structured Interview for DSM-IV Personality (coded: $0=$ not present or limited to rare isolated examples; 1 = subthreshold; 2 = present; $3=$ strongly present) (Pfohl et al . 1995; Rosenström et al. 2017). At wave 1, a face-to-face interview was conducted for all but 231 individuals who were interviewed over telephone for practical reasons. All the wave 2 interviews were conducted by telephone. Interviewers were mainly senior clinical psychology graduate students 
and experienced psychiatric nurses. Each twin in a pair was interviewed by a different interviewer. A lifetime estimate is dependent on the interviewees' limited memory. To maximize lifetime coverage of disorder occurrence, we counted diagnosis in either study wave as a case. For economic reasons, some (see below) of the disorders were not interviewed in the $2^{\text {nd }}$ wave. We used data on all psychiatric disorders seen in previous general-factor studies that both were available to us and had more than 100 observed cases or sub-threshold cases (excluding conduct disorder, which is considered a childhood precursor of antisocial personality).

Alcohol use disorder was indicated by either alcohol abuse (F10.1 in ICD-10) or dependence (F10.2). Substance use disorder was indicated by any of opioid abuse/dependence (F11.1 or F11.2), cannabis abuse/dependence (F12.1 or F12.2), sedative abuse/dependence (F13.1 or F13.2), cocaine abuse/dependence (F14.1 or F14.2), amphetamine abuse/dependence (F15.1 or F15.2), hallucinogen abuse/dependence (F16.1 or F16.2), or inhalant abuse/dependence (F18.1 or F18.2). Due to its rarity and possible underreporting, we also assigned substance use disorder for those sub-threshold cases who admitted in interview having used illegal drugs more than ten times. Other analyzed variables were any Major Depressive Episode (F30-39), Dysthymic disorder (F34.1), Panic attack (F40-48), Agoraphobia (F40.0), Social phobia (F40.1), Specific phobia (any of F40.21-25), Generalized anxiety disorder (F41.1), Antisocial personality traits (an ordinal count of 0, 1, 2, or 3 or more DSM-IV criteria of antisocial personality disorder, excluding childhood conduct disorder criterion), Psychotic-like experiences score, a 3-category ordinal variable coded by values 0,1 , and 2 , constructed from 22 symptoms screen in the psychosis module of the CIDI (Nesvåg et al. 2017), and Manic experiences score, constructed from symptoms assessed in the CIDI mania module.

From the above list of variables, wave 2 assessment re-evaluated everything else except substance use disorder and psychotic-like and manic experiences. In addition, the wave 2 assessment included the Big Five Inventory (BFI) administered through a mailed questionnaire. The $\mathrm{BFI}$ is a 44-item inventory that measures an individual on the Big Five personality traits (John \& 
Srivastava 1999). The inventory assigns for each person a value on five continuously distributed traits (standardized sum scores) that currently are perhaps the most frequently used traits in personality research (John et al. 2008). The traits are Extraversion, Agreeableness, Conscientiousness, Neuroticism, and Openness. These traits form a comprehensive system for describing personality, which has been frequently used to predict important life outcomes, including risk for psychopathology (Kotov et al. 2010).

The DSM-5 includes two models of personality pathology, old and new/emerging (American Psychiatric Association 2013). The new approach includes five personality traits conceptualized as maladaptive forms of personality traits: Negative emotionality (or affectivity; vs. emotional stability), Detachment (vs. extraversion), Antagonism (vs. agreeableness), Disinhibition (vs. conscientiousness), and Psychoticism (vs. lucidity). We included the new system as it represented ongoing progress in the field, was a complete trait system, and strongly overlapped with old personality disorders in a previous study of the same sample (Reichborn-Kjennerud et al. 2017). The same 36-item PID-5-NBF instrument has been used previously (Personality Inventory for DSM-5, Norwegian Brief Form), but here we excluded the trait Compulsivity that did not make it into DSM-5 (Reichborn-Kjennerud et al. 2017). All continuous-valued (trait) variables were standardized to mean of zero and variance of one.

\section{Statistics}

Variants of the correlated-factor and/or bi-factor analysis models have been frequently applied in factorial studies of psychopathology (Krueger 1999; Lahey et al. 2012; Caspi et al. 2014; Lahey et al. 2011; Pettersson et al. 2016; Waldman et al. 2016; de Jonge et al. 2017). In exploratory factor analysis (Lawley \& Maxwell 1971), factor solutions are largely data-driven and need to be rotated to improve interpretability, without changing the overall model fit. Rotation methods can provide correlated and uncorrelated factors and bi-factor solutions (Jennrich \& Bentler 2011, 2012). Here we 
investigate two such fit-equivalent solutions: (i) a correlated-factor model that has possibly correlated but otherwise coequally treated factors and (ii) a bi-factor solution that has a generalliability factor plus specific disorder-group factors that are uncorrelated with the general factor.

In confirmatory versions of factor analytic methods, researchers decide $a$ priori which items are to 'measure' (load on) which factors and then examine ensuing model fits. Here, in exploratory factor analysis, we do not make a priori assumptions. The aim is to explore what latent structures could account for the observed comorbidity between current psychiatric constructs rather than use the constructs directly as 'measurement items' (i.e., the aim is not to test a 'clean' structure without any cross-loading) (Asparouhov \& Muthén 2009). In exploratory settings, similarity between two vectors (lists) of factor loadings is frequently quantified using congruence coefficient, $\varphi$, taking values between -1 and 1 (Tucker 1951; Lorenzo-Seva \& ten Berge 2006; Abdi 2007). Values in the range $0.85-0.94$ are considered to reflect "fair similarity" and values above 0.95 indicate that two factors can be "considered equal" (Lorenzo-Seva \& ten Berge 2006).

We investigated exploratory correlated-factor (i.e., Geomin rotation) and bi-factor (i.e., Bi-geomin rotation) analysis solutions to understand the patterning of correlations among the different psychiatric disorders and personality traits (Jennrich \& Bentler 2012). Specific-factor intercorrelations were allowed. Mean- and variance adjusted weighted least squares estimator of Mplus software was used because we had a mixture of binary, ordinal, and continuous variables (Asparouhov \& Muthén 2009). A sandwich-version of the estimator was used to take in account and adjust for the non-independence of the nested twin data (Asparouhov 2005). Ordinal-valued variables were always modeled using a liability-threshold model (Falconer 1965; Olsson 1979). The optimal number of latent factors in factor analysis was determined using Horn's parallel analysis method, applied to the eigenvalues of the Mplus-estimated polychoric correlation matrix (Horn 1965; Garrido et al. 2013; Rosenström et al. 2017; see an intuitive explanation in the supplementary material). Parallel analysis was preferred over methods based on likelihood-ratio test because 
necessary assumptions of such tests are violated under over-factoring (Hayashi et al. 2007; Drton 2009). It was also preferred over many fit indices that lose their meaning in ordinal-data factor analysis (Garrido et al. 2016; Xia \& Yang, 2018), but we present few typical indices (RMSEA, CFI, TLI) to satisfy curiosity of many readers.

The twin "ACE" model of behavior genetics was used to estimate heritability of the factors (Neale \& Cardon 1992; see also our supplementary explanation). Twin models were fit in Open Mx package version 2.7.11, under R software version 3.4.1, using full-information maximum likelihood estimation (Enders \& Bandalos 2001; Neale et al. 2016).

In the supplementary sensitivity analysis, we discuss the importance of controlling for measurement-related factors in more detail. In short, Extreme response style (ERS) and Acquiescent response style (ARS) variables were computed from the BFI items according to a previously used formula (Wetzel et al. 2016). Response style variables show characteristics of stable individual differences (Weijters et al. 2010a, 2010b; Wetzel et al. 2016). We found a clear response style factor unrelated to psychopathology, and therefore, pre-processed all self-reported personality trait scores by regressing out ERS and ARS factors before entering them to the factor analyses of the main text. Alternative solutions are discussed and shown in the online supplement.

\section{Results}

Table 1 provides a summary of available observations and prevalence of psychiatric disorders in the sample. The personality traits are not shown in the table because they were standardized sum scores (mean 0, variance 1; each had between 2293 and 2297 valid observations; supplementary Table S3 for unstandardized averages). We discuss first the correlated-factor and bi-factor analyses and their supplementary sensitivity analyses, and then the biometric partitioning of the resulting factor scores. 
Three factors were evident in the joint data analyses on disorders and personality traits (Figure 1a). Both correlated-factor and bi-factor solutions were fit to the data (Table 2 displays the factor loadings and Figure $1 \mathrm{~b}$ and $1 \mathrm{c}$ illustrate the structure). In the correlated-factor solution, we observed a psychopathology $(p)$ factor without noticeable loadings on personality, but with strong correlation to another factor (personality pathology) that loaded on all other personality traits except openness. We named this factor "personality pathology" because 'pathological' PID-5-NBF traits loaded positively on it and the loading pattern of the FFI traits on it was an inverse of the "general factor of personality" that assesses positive versus negative aspects of personality, emotionality, motivation, well-being, and self-esteem (Musek, 2007). The third factor cross-loaded on typical externalizing behaviors and correlated negatively with the first $(p)$ factor.

However, a rotation of this exploratory factor analysis solution allows another interpretation of the same statistical model having exactly the same model fit (i.e., RMSEA $=0.05$ with $90 \% \mathrm{Cl}=0.047-0.052, \mathrm{CFI}=0.914, \mathrm{TLI}=0.879$; the numbers are the exact same for the correlated- and bi-factor models). In this bi-factor rotation, the general $p$ factor loads on all disorders and almost all personality traits. The two residual group factors are uncorrelated with the $p$ factor and have loadings on the typical internalizing and externalizing disorders and some of the associated personality traits. The bi-factor rotation makes the concepts of internalizing and externalizing disorders more visible by isolating the overlapping part of psychiatric comorbidity and personality content into the general $p$ factor. It was a clinically interpretable model in the sense that there was no need to consider further latent factors that give rise to inter-factor correlations and it contained clear-cut factors for internalization and externalization. The bi-factor model incorporated personality traits and psychiatric disorders in a joint model instead of modeling pathological personality as a correlate of psychopathology.

All the factors of the bi-factor model were noticeably different from the factors of the correlated-factor model in all cross-comparisons $(-0.71<\varphi<0.78)$. In contrast, the same index 
suggested that the general-factor loadings for interview diagnoses in the bi-factor model could be "considered equal" ( $\varphi=0.991$ in a comparison with a strictly equal-loadings factor). When taking absolute values, uniformity held for all the general-factor loadings, including personality traits $(\varphi=$ 0.962 , and $\varphi=0.983$ when excluding Openness).

Supplementary sensitivity analyses of the joint factorial structure

We also investigated factor solutions with many other rotations and sets of input variables, although we chose to present only those in Table 2 in the main text for the sake of clarity. When we did not remove response style effects from the personality variables, we observed a similar bi-factor solution as in Table 2, but with an additional difficult-to-interpret specific factor for personality (supplementary Table S1). Inserting our response style variables into the factor model revealed that one of the four factors was related to response styles and unrelated to psychopathology (supplementary Table S2). For the sake of conciseness, pertinent response styles were regressed out, but this did not have a major influence on other structure than the response style factor.

Heritability patterns of factor scores

Heritability estimates (proportion of additive-genetic variance; $h^{2}$ ) of factor scores derived from the correlated-factor model were $48 \%(95 \% \mathrm{Cl}=42-55 \%)$ for the $p$ factor, $41 \%(\mathrm{Cl}=35-48 \%)$ for the personality pathology factor, and $43 \%(\mathrm{Cl}=36-50 \%)$ for the externalizing factor. Heritability estimates of the bi-factor scores were $48 \%(\mathrm{Cl}=41-54 \%)$ for the $p$ factor, $35 \%(\mathrm{Cl}=28-42 \%)$ for the internalizing factor, and $37 \%(\mathrm{Cl}=31-44 \%)$ for the externalizing factor. We did not observe statistically significant effects of twin pairs' shared environment. Overall, the correlated-factor model implied higher phenotypic and genetic factor correlations than the bi-factor model (Table 3). 


\section{Discussion}

We found three factors underlying the joint structure of 11 psychiatric disorders and 10 normal and pathological personality traits. This structure was explored using two statistically equivalent exploratory factor models, correlated-factor and bi-factor models that still provided different interpretations regarding the joint structure of psychiatric disorders and personality and on comorbidity. According to the correlated-factor model, psychiatric disorders, personality traits, and externalizing behaviors all reflected separate underlying factors that were inter-correlated and similarly heritable [41-48\%; a typical range (Polderman et al. 2015)]. According to the alternative bifactor rotated solution, all disorders and almost all personality traits reflected a general dimension of psychopathology ( $48 \%$ heritable $p$ factor) plus less-heritable specific residual factors for internalizing and externalizing traits ( $35 \%$ and $37 \%$ heritable, respectively). The latter model was more parsimonious in that it had fewer and lower unexplained factor correlations and cross-loadings (but not different in terms of statistical fit). For both the models, genetic and environmental factor-score correlations differed from phenotypically observed correlations, but in the bi-factor model genetic correlations between the general and the specific factors remained moderate. This makes the general factor perhaps a more salient (less confounded/correlated) target for genome-wide and neuroscientific studies of psychiatric comorbidity compared to the disorder factor from the correlated-factor model, as explained below and in pertinent literature (Lahey et al. 2017; Caspi \& Moffitt 2018; Oltmanns et al. 2018).

The findings from the joint correlated-factor model of psychiatric disorders and normative and pathological personality conceptualized personality traits and psychiatric disorders as reflecting separate correlated factors. Under this theory, a researcher interested in associations between the disorder liability and third factors (e.g., a gene and an exposure) would typically adjust for 'confounding' personality, thus discarding the variance overlapping with it. In contrast, the $p$ factor from the bi-factor model incorporates disorder-overlapping parts of personality and rules out the rest. In theory, the bi-factor model is practically useful in the sense that the $p$ factor is pertinent 
to comorbidity research without further difficult-to-interpret controls for correlated residual personality, normative or pathological. In practice, this held better for genetic than for environmental influences, for which residual correlations remained in factor scores (Table 3). At this point, we do not take a strong position for or against either explorative structural model, but instead emphasize the higher level of parsimony of the bi-factor model, its connections with the existing literature, and its potential for generating hypotheses for future research.

For example, the personality trait antagonism is typically associated with externalizing psychiatric disorders (e.g., substance abuse), which involve aggression. On the other hand, internalizing disorders (e.g., depression) are typically associated with personality traits such as neuroticism that involves frequent negative emotions, including anger (Kotov et al. 2010). In the correlated-factor model, such overlapping psychological content was expressed both in correlations between assumed latent factors and in cross-loadings (i.e., in some measured traits reflecting one part one factor, another part another factor). The same model can be expressed in a perhaps more conceptually trackable (bi-factor) form, with less-correlated factors and with cross-loadings constrained to general factor only (Figure 1). These fit-equivalent interpretations (rotations) generate distinct hypotheses for future research. In the example case, the correlated-factors model implies that high antagonism is directly indicative of high risk for personality pathology and externalizing traits, whereas the bi-factor model implies that antagonism is instead indicative of general psychopathology with a lack of 'normal' internalizing tendency. This distinction can only be seen in the multivariate context, yet, might turn out clinically significant in the future research.

It is not well-understood what might give rise to a general factor of psychopathology, but several suggestive findings and proposals exist. Different authors have linked the $p$ factor with functional arguments related either to life-history strategies (Del Giudice 2014), to balance in fast versus slow cognitive processes (Carver et al. 2017), to general integrity of the nervous system (Caspi et al. 2014) , and/or to inefficient intrinsic functional brain connectivity (Elliott et al. 2018). Empirical 
studies have reported physiological findings common to multiple psychiatric disorders, such as changes in volume of overlapping brain areas (Goodkind et al. 2015), shared cortical gene expression patterns (Gandal et al. 2018), overlapping genetic correlates (Lahey et al. 2011; Geschwind \& Flint 2015; Neumann et al. 2016; Pettersson et al. 2016; Wang et al. 2017), and lower than average performance level in tests of intelligence (Caspi et al. 2014; Neumann et al. 2016). Capturing possible shared etiologies of multiple psychiatric disorders to a single phenotype (factor) rather than in correlations between multiple phenotypes (factors) has potential to bring clarity to psychiatric nosology. This is a major argument in favor of the bi-factor model. A general factor model of psychopathology and personality may offer scientific parsimony and clinical utility by treating psychiatric comorbidity as a measurable construct instead of an unexplained correlation.

In a partial contrast, Oltmanns et al. (2018) argued that modeling of general factors may not be etiologically informative, as they might arise from impairments and dysfunctions that are secondary to underlying causes. It remains unclear how the hypothesis links with the abovementioned etiologic factors and why the etiology is so different for psychiatric disorders in comparison to other (e.g., neurological) disorders that also imply severe impairment and dysfunction (Wang et al., 2017; Brainstorm Consortium, 2018). Empirically, Oltmanns et al. (2018) solution resembled our correlated-factor model, albeit with stronger factor correlations that may relate to use of more measurement items in their study or to their use of confirmatory framework wherein non-pure indicators can inflate absolute factor correlations (Asparouhov \& Muthen, 2009; Morin et al. 2016).

Sometimes researchers try to infer psychological content of the general factor based on comparatively high loading magnitudes of given disorders on the general factor and lack of specific factors for the disorders, as has been observed for psychotic disorders in comparison to other disorders (Caspi et al. 2014; Carver et al. 2017). However, we observed similar loading magnitudes for psychotic-like and manic experiences as for other disorders, and our general factor 
was highly congruent with uniform loadings for all disorders and personality traits. In fact, when we computed congruence coefficients between a uniformly loading factor and the 'psychosis-heavy' general factor reported in Caspi et al. (2014), it too exceeded a recommended cut off for two factors being “considered equal" (i.e., $\varphi=0.962>0.95$ ) (Lorenzo-Seva \& ten Berge 2006). Eid et al. (2017) noted that finding one non-significant specific factor is common in confirmatory bi-factor analyses, which they attributed to low identifiability and to a need to a priori anchor the general factor on some variable(s). Thus, use of pre-established and clear criteria for inferring differential loading magnitudes and patterns would help in distinguishing them from sampling noise, near-equivalent solutions, and other idiosyncratic variation. The higher loadings on psychotic versus other disorders observed by Caspi et al. (2014) might also relate to their very high participant retention rate, including psychotic individuals. If unbiased, our uniform factor loadings imply that all variables reflect the factor equally much in terms of their overall variance. In bi-factor models, however, one needs to assess several variables jointly to separate their residual and group factors from the general factor score.

It is a limitation that exploratory correlated-factor and bi-factor models are statistically equivalent, having equal fit to data. One model may offer a more parsimonious interpretation than the other, but further studies are needed before either of the models can be claimed to reveal underlying etiologic processes. For example, longitudinal studies could be helpful, as well as biometric path studies (Franić et al. 2013) preferably in larger datasets compared to this study. On the positive side, much of the criticism and problems pertinent to confirmatory bi-factor modeling do not carry over to the present case of exploratory rotations (Asparouhov \& Muthén 2009; Jennrich \& Bentler 2011, 2012; Eid et al. 2017). Furthermore, the latent distribution of factor models (a multivariate normal distribution) is typically chosen to facilitate computation, not because it necessarily best reflects 'the nature' (Lei \& Lomax 2005); here we developed some substantive arguments to distinguish between rotations and also technical arguments can be developed when multivariate normality is not assumed (Hyvärinen et al. 2001; see also our supplementary material). 
In addition, our estimates of heritability are lower bounds (i.e., likely underestimates) because, for computational reasons, we had to use a two-step procedure with heritability estimation performed on pre-computed phenotype-based estimates of factor scores (van den Berg et al. 2007). In principle, factor and biometric models can be fully combined (Neale \& Cardon 1992; Franić et al. 2013; Rosenström et al. 2017). In practice, our attempts were thwarted either by computational demands of multivariate integration in case of ordinal-valued full-information approach or by instability of approaches like weighted least squares estimation within relatively small zygosity sub-groups. Furthermore, our estimates could be subject to a degree of recruitment and attrition bias in the sample, or bias from just single occasion of self-reporting as opposed to two interviews, although an attrition study only indicated moderate selection towards good health without bias in genetic or environmental covariance structures (Tambs et al. 2009).

In summary, allowing for a correction for response styles, inter-correlations between psychiatric disorders and pathological and normative personality traits could be explained with three factors. Whereas a correlated-factor model led to distinct (but correlated) psychiatric-disorder and personality-pathology factors, an equally-fitting bi-factor model led to an overarching shared psychopathology factor for disorders and normative and pathological personality traits, plus orthogonal domain-specific factors for internalizing and externalizing disorders and traits. The latter interpretation of the data promotes a joint etiologic model of comorbid personality pathology and general psychopathology, with potential to increase theoretical and diagnostic parsimony in psychiatry and to provide more interpretable target phenotypes for genetic studies.

\section{Acknowledgements and Disclosures}

We acknowledge funding from the US National Institutes of Health and National Institute on Drug Abuse (1R01DA037558-01A1), the Research Council of Norway $(226985 ; 240061)$, the Norwegian Foundation for Health and Rehabilitation, the Norwegian Council for Mental Health, and the 
European Commission under the program "Quality of Life and Management of the Living Resources" of the Fifth Framework Program (QLG2-CT-2002-01254). THR had full access to all the data in this study and takes responsibility for the integrity of the data and the accuracy of the data analysis. The funding sources had no role in the design and conduct of the study; collection, management, analysis, and interpretation of the data; preparation, review, or approval of the manuscript; and decision to submit the manuscript for publication. All the authors report no conflicts of interest. The authors assert that all procedures contributing to this work comply with the ethical standards of the relevant national and institutional committees on human experimentation and with the Helsinki Declaration of 1975, as revised in 2008.

\section{References}

Abdi H (2007). RV Coefficient and Congruence Coefficient. In Encyclopedia of Measurement and Statistics. Sage: Thousand Oaks, California.

Achenbach TM (1966). The classification of children's psychiatric symptoms: a factor-analytic study. Psychological Monographs 80, 1-37.

American Psychiatric Association (2013). Diagnostic and Statistical Manual of Mental Disorders, Fifth Edition. American Psychiatric Association: Arlington, VA.

Asparouhov T (2005). Sampling weights in latent variable modeling. Structural Equation Modeling 12, 411-434.

Asparouhov T, Muthén B (2009). Exploratory structural equation modeling. Structural Equation Modeling: A Multidisciplinary Journal 16, 397-438.

van den Berg SM, Glas CAW, Boomsma DI (2007). Variance decomposition using an IRT measurement model. Behavior Genetics 37, 604-616.

Bonifay W, Cai L (2017). On the complexity of item response theory models. Multivariate Behavioral Research 52, 465-484.

Borsboom D (2017). A network theory of mental disorders. World Psychiatry 2017, 5-13.

Brainstorm Consortium (2018). Analysis of shared heritability in common disorders of the brain. Science 360, pii: eaap8757. doi: 10.1126/science.aap8757

Carver CS, Johnson SL, Timpano KR (2017). Toward a functional view of the $p$ factor in psychopathology. Clinical Psychological Science 5, 880-889. 
Caspi A, Houts RM, Belsky DW, Goldman-Mellor SJ, Harrington H, Israel S, Meier MH, Ramrakha S, Shalev I, Poulton R, Moffitt TE (2014). The p factor: One general psychopathology factor in the structure of psychiatric disorders? Clinical Psychological Science 2, 119-137.

Caspi A, Moffitt TE (2018). All for one and one for all: Mental disorders in one dimension. The American Journal of Psychiatry [Epub ahead of print], doi:10.1176/appi.ajp.2018.17121383.

Cuthbert BN (2014). The RDoC framework: facilitating transition from ICD/DSM to dimensional approaches that integrate neuroscience and psychopathology. World Psychiatry 13, 28-35.

Czajkowski N, Aggen SH, Krueger RF, Kendler KS, Neale MC, Knudsen GP, Gillespie NA, Røysamb E, Tambs K, Reichborn-Kjennerud T (2018). A twin study of normative personality and DSM-IV personality disorder criterion counts: Evidence for separate genetic influences. American Journal of Psychiatry 175, 649-656.

Del Giudice M (2014). An evolutionary life history framework for psychopathology. Psychological Inquiry 25, 261-300.

Del Giudice $\mathbf{M}$ (2016). The life history model of psychopathology explains the structure of psychiatric disorders and the emergence of the $p$ factor: A simulation study. Clinical Psychological Science 4, 299-311.

Drton M (2009). Likelihood ratio tests and singularities. The Annals of Statistics 37, 979-1012.

Eid M, Geiser C, Koch T, Heene M (2017). Anomalous results in G-factor models: Explanations and alternatives. Psychological Methods 22, 541-562.

Elliott ML, Romer A, Knodt AR, Hariri AR (2018). A connectome-wide functional signature of transdiagnostic risk for mental illness. Biological Psychiatry [Epub ahead of print], doi:10.1016/j.biopsych.2018.03.012.

Enders CK, Bandalos DL (2001). The relative performance of full information maximum likelihood estimation for missing data in structural equation models. Structural Equation Modeling 8, 430-457.

Falconer DS (1965). The inheritance of liability to certain diseases, estimated from the incidence among relatives. Annals of Human Genetics 29, 51-76.

Franić S, Dolan CV, Borsboom D, Hudziak JJ, van Beijsterveldt CEM, Boomsma DI (2013). Can genetics help psychometrics? Improving dimensionality assessment through genetic factor modeling. Psychological Methods 18, 406-433.

Gandal MJ, Haney JR, Parikshak NN, Leppa V, Ramaswami G, Hartl C, Schork AJ, Appadurai V, Buil A, Werge TM, Liu C, White KP, Consortium C, Consortium P, Group iPSYCH-BW, Horvath S, Geschwind DH (2018). Shared molecular neuropathology across major psychiatric disorders parallels polygenic overlap. Science 359, 693-697.

Garrido LE, Abad FJ, Ponsoda V (2013). A new look at Horn's parallel analysis with ordinal variables. Psychological Methods 18, 454-474.

Garrido LE, Abad FJ, Ponsoda V (2016). Are fit indices really fit to estimate the number of factors with categorical variables? Some cautionary findings via Monte Carlo simulation. Psychological Methods 21, 93-111. 
Geschwind DH, Flint J (2015). Genetics and genomics of psychiatric disease. Science 349, 1489-1494.

Goodkind M, Eickhoff SB, Oathes DJ, Jiang Y, Chang A, Jones-Hagata LB, Ortega BN, Zaiko YV, Roach EL, Korgaonkar MS, Grieve SM, Galatzer-Levy I, Fox PT, Etkin A (2015). Identification of a common neurobiological substrate for mental illness. JAMA psychiatry 72, 305-315.

Haslam N, Holland E, Kuppens P (2012). Categories versus dimensions in personality and psychopathology: a quantitative review of taxometric research. Psychological Medicine 42, 903-920.

Hayashi K, Bentler PM, Yuan K-H (2007). On the likelihood ratio test for the number of factors in exploratory factor analysis. Structural Equation Modeling 14, 505-526.

Horn JL (1965). A rationale and test for the number of factors in Factor Analysis. Psychometrika 30, 179-185.

Hyvärinen A, Karhunen J, Oja E (2001). Independent Component Analysis. Wiley, New York.

Jennrich RI, Bentler PM (2011). Exploratory bi-factor analysis. Psychometrika 76, 537-549.

Jennrich RI, Bentler PM (2012). Exploratory bi-factor analysis: the oblique case. Psychometrika 77, 442-454.

John OP, Naumann LP, Soto CJ (2008). Paradigm shift to the integrative Big Five trait taxonomy: History, measurement, and conceptual issues. In Hand book of personality: Theory and research 3rd edn Eds OP John, RW Robins \& LA Pervin, pp114-158. The Guilford Press: New York, USA.

John OP, Srivastava S (1999). The Big-Five trait taxonomy: History, measurement, and theoretical perspectives. In Handbook of personality: Theory and research 2nd edn Eds LA Pervin \& OP John, pp102-138. Guilford Press: New York.

de Jonge P, Wardenaar KJ, Lim CCW, Aguilar-Gaxiola S, Alonso J, Andrade LH, Bunting B, Chatterji S, Ciutan M, Gureje O, Karam EG, Lee S, Medina-Mora ME, Moskalewicz J, Navarro-Mateu F, Pennell B-E, Piazza M, Posada-Villa J, Torres Y, Kessler RC, Scott K (2017). The cross-national structure of mental disorders: results from the World Mental Health Surveys. Psychological Medicine 48, 20732084.

Kotov R, Gamez W, Schmidt F, Watson D (2010). Linking 'big' personality traits to anxiety, depressive, and substance use disorders: a meta-analysis. Psychological Bulletin 136, 768-821.

Kotov R, Krueger RF, Watson D, Achenbach TM, Althoff RR, Bagby RM, Brown TA, Carpenter WT, Caspi A, Clark LA, Eaton NR, Forbes MK, Forbush KT, Goldberg D, Hasin D, Hyman SE, Ivanova MY, Lynam DR, Markon K, Miller JD, Moffitt TE, Morey LC, Mullins-Sweatt SN, Ormel J, Patrick CJ, Regier DA, Rescorla L, Ruggero CJ, Samuel DB, Sellbom M, Simms LJ, Skodol AE, Slade T, South SC, Tackett JL, Waldman ID, Waszczuk MA, Widiger TA, Wright AGC, Zimmerman M (2017). The Hierarchical Taxonomy of Psychopathology (HiTOP): A dimensional alternative to traditional nosologies. Journal of Abnormal Psychology 126, 454-477.

Krueger RF (1999). The structure of common mental disorders. Archives of General Psychiatry 56, 921-926.

Lahey BB, Applegate B, Hakes JK, Zald DH, Hariri AR, Rathouz PJ (2012). Is there a general factor of prevalent psychopathology during adulthood? Journal of Abnormal Psychology 121, 971-977. 
Lahey BB, Krueger RF, Rathouz PJ, Waldman ID, Zald DH (2017). Validity and utility of the general factor of psychopathology. World Psychiatry 16, 142-144.

Lahey BB, Van Hulle CA, Singh AL, Waldman ID, Rathouz PJ (2011). Higher-order genetic and environmental structure of prevalent forms of child and adolescent psychopathology. Archives of General Psychiatry 68, 181-189.

Lawley DN, Maxwell AE (1971). Factor Analysis as a Statistical Method. 2nd edn. Butterworths \& Co: London.

Lei M, Lomax RG (2005). The effect of varying degrees of nonnormality in structural equation modeling. Structural Equation Modeling: A Multidisciplinary Journal 12, 1-27.

Lorenzo-Seva U, ten Berge JMF (2006). Tucker's congruence coefficient as a meaningful index of factor similarity. Methodology: European Journal of Research Methods for the Behavioral and Social Sciences 2, 57-64.

Mansolf M, Reise SP (2017). When and why the second-order and bifactor models are distinguishable. Intelligence 61, 120-129.

Markon KE, Chmielewski M, Miller CJ (2011). The reliability and validity of discrete and continuous measures of psychopathology: A quantitative review. Psychological Bulletin 137, 856-879.

Morin AJS, Arens AK, Marsh HW (2016). A bifactor exploratory structural equation modeling framework for the identification of distinct sources of construct-relevant psychometric multidimensionality. Structural Equation Modeling: A Multidisciplinary Journal 23, 116-139.

Musek J (2007). A general factor of personality: Evidence for the Big One in the five-factor model. Journal of Research in Personality 41, 1213-1233.

Neale MC, Cardon LR (1992). Methodology for Genetic Studies of Twins and Families. Kluwer Academic Publishers: Dordrecht, The Netherlands.

Neale MC, Hunter MD, Pritikin JN, Zahery M, Brick TR, Kirkpatrick RM, Estabrook R, Bates TC, Maes HH, Boker SM (2016). OpenMx 2.0: Extended structural equation and statistical modeling. Psychometrika 81, 535-549.

Nesvåg R, Reichborn-Kjennerud T, Gillespie NA, Knudsen GP, Bramness JG, Kendler KS, Ystrom E (2017). Genetic and environmental contributions to the association between cannabis use and psychotic-like experiences in young adult twins. Schizophrenia Bulletin 43, 644-653.

Neumann A, Pappa I, Lahey BB, Verhulst FC, Medina-Gomez C, Jaddoe VW, Bakermans-Kranenburg MJ, Moffitt TE, van IJzendoorn MH, Tiemeier H (2016). Single nucleotide polymorphism heritability of a general psychopathology factor in children. Journal of the American Academy of Child and Adolescent Psychiatry 55, 1038-1045.e4.

Nilsen TS, Knudsen GP, Gervin K, Brandt I, Røysamb E, Tambs K, Orstavik R, Lyle R, ReichbornKjennerud T, Magnus P, Harris JR (2013). The Norwegian Twin Registry from a public health perspective: a research update. Twin Research and Human Genetics 16, 285-295.

Olsson U (1979). Maximum likelihood estimation of the polychoric correlation coefficient. Psychometrika 44, 443-460. 
Oltmanns JR, Smith GT, Oltmanns TF, Widiger TA (2018). General factors of psychopathology, personality, and personality disorder: Across domain comparisons. Clinical Psychological Science [Epub ahead of print], doi:10.1177/2167702617750150.

Pettersson E, Larsson H, Lichtenstein P (2016). Common psychiatric disorders share the same genetic origin: a multivariate sibling study of the Swedish population. Molecular Psychiatry 21, 717721.

Pfohl B, Blum N, Zimmerman M (1995). Structured Interview for DSM-IV Personality (SIDP-IV). University of lowa, Department of Psychiatry: lowa City.

Polderman TJC, Benyamin B, de Leeuw CA, Sullivan PF, van Bochoven A, Visscher PM, Posthuma D (2015). Meta-analysis of the heritability of human traits based on fifty years of twin studies. Nature Genetics 47, 702-709.

Reichborn-Kjennerud T, Krueger RF, Ystrom E, Torvik FA, Rosenström TH, Aggen SH, South SC, Neale MC, Knudsen GP, Kendler KS, Czajkowski NO (2017). Do DSM-5 Section II personality disorders and Section III personality trait domains reflect the same genetic and environmental risk factors? Psychological Medicine 47, 2205-2215.

Rosenström T, Jokela M (2017). A parsimonious explanation of the resilient, undercontrolled, and overcontrolled personality types. European Journal of Personality 31, 658-668.

Rosenström T, Ystrom E, Torvik FA, Czaijkowski NO, Gillespie NA, Aggen SH, Krueger RF, Kendler KS, Reichborn-Kjennerud T (2017). Genetic and environmental structure of DSM-IV criteria for Antisocial Personality Disorder: a twin study. Behavior Genetics 47, 265-277.

Tackett JL, Lahey BB, van Hulle C, Waldman I, Krueger RF, Rathouz PJ (2013). Common genetic influences on negative emotionality and a general psychopathology factor in childhood and adolescence. Journal of Abnormal Psychology 122, 1142-1153.

Tambs K, Rønning T, Prescott CA, Kendler KS, Reichborn-Kjennerud T, Torgersen S, Harris JR (2009). The Norwegian Institute of Public Health twin study of mental health: examining recruitment and attrition bias. Twin Research and Human Genetics 12, 158-168.

Tucker LR (1951). A method for the synthesis of factor analysis studies. Technical report no. 984 Personnel Research Section. Department of the Army: Washington, DC.

Xia Y, Yang Y (2018). RMSEA, CFI, and TLI in structural equation modeling with ordered categorical data: The story they tell depends on the estimation methods. Behavior Research Methods [Epub ahead of print]. doi: 10.3758/s13428-018-1055-2

Waldman ID, Poore HE, van Hulle C, Rathouz PJ, Lahey BB (2016). External validity of a hierarchical dimensional model of child and adolescent psychopathology: Tests using confirmatory factor analyses and multivariate behavior genetic analyses. Journal of Abnormal Psychology 125, 10531066.

Wang K, Gaitsch H, Poon H, Cox NJ, Rzhetsky A (2017). Classification of common human diseases derived from shared genetic and environmental determinants. Nature Genetics 49, 1319-1325.

Weijters B, Geuens M, Schillewaert N (2010a). The individual consistency of acquiescence and extreme response style in self-report questionnaires. Applied Psychological Measurement 34, 105121. 
Weijters B, Geuens M, Schillewaert N (2010b). The stability of individual response styles. Psychological Methods 15, 96-110.

Wetzel E, Lüdtke O, Zettler I, Böhnke JR (2016). The stability of extreme response style and acquiescence over 8 years. Assessment 23, 279-291.

Widiger TA, Mullins-Sweatt SN (2009). Five-factor model of personality disorder: A proposal for DSM-V. Annual Review of Clinical Psychology 5, 197-220.

Wittchen HU, Pfister H (1997). DIA-X Interview (M-CIDI). Swets \& Zeitlinger: Frankfurt. 


\section{Tables}

Table 1. Lifetime prevalence estimates for the disorders

\begin{tabular}{rcc}
\hline Variable & $\boldsymbol{n}_{\text {available }}$ & Prevalence \\
Alcohol use disorder & 2339 & 0.150 \\
Substance use disorders & 2773 & 0.067 \\
Major depressive episode & 2360 & 0.284 \\
Panic attack & 2312 & 0.116 \\
Agoraphobia & 2302 & 0.083 \\
Social phobia & 2304 & 0.082 \\
Specific phobias & 2383 & 0.289 \\
Generalized anxiety disorder & 2290 & 0.047 \\
Antisocial personality traits & 2796 & $0.354^{\dagger}$ \\
Psychotic-like experiences & 2791 & 0.178 \\
Manic experiences & 2779 & 0.137 \\
\hline
\end{tabular}

$\lceil$ "Prevalence" of antisocial traits is instead an average over the categorical weights (see methods) 
Table 2. Exploratory factor loadings.

\begin{tabular}{|c|c|c|c|c|c|c|c|}
\hline \multirow{3}{*}{$\begin{array}{l}\text { Dataset } \\
\text { Interview }\end{array}$} & \multirow[b]{2}{*}{ Variable } & \multicolumn{3}{|c|}{ Factors from correlated-factor rotation } & \multicolumn{3}{|c|}{ Factors from bi-factor rotation } \\
\hline & & $\begin{array}{c}\text { Factor \#1: } \\
\text { “Psychopathology" }\end{array}$ & $\begin{array}{l}\text { Factor \#2: } \\
\text { "Personality } \\
\text { pathology" }\end{array}$ & $\begin{array}{c}\text { Factor \#3: } \\
\text { “Externalizing” }\end{array}$ & $\begin{array}{l}\text { General factor: } \\
\text { "Psychopathology" }\end{array}$ & $\begin{array}{l}\text { Specific factor } \\
\text { \#1: } \\
\text { “Internalizing” }\end{array}$ & $\begin{array}{l}\text { Specific factor } \\
\# 2: \\
\text { “Externalizing” }\end{array}$ \\
\hline & Alcohol use disorder & 0.475 & -0.002 & $\mathbf{0 . 5 3 7}$ & 0.542 & -0.028 & 0.361 \\
\hline & Substance use disorders & 0.658 & -0.097 & 0.557 & 0.586 & 0.095 & 0.462 \\
\hline & Major depressive episode & 0.587 & 0.171 & 0.012 & 0.499 & 0.445 & 0.012 \\
\hline & Panick attack & 0.732 & 0.137 & 0.043 & 0.575 & 0.533 & 0.074 \\
\hline & Agoraphobia & 0.817 & 0.161 & -0.034 & 0.608 & 0.656 & 0.037 \\
\hline & Social phobia & 0.683 & 0.268 & -0.022 & 0.618 & 0.546 & -0.046 \\
\hline & Specific phobias & 0.471 & 0.139 & -0.06 & 0.369 & 0.409 & -0.027 \\
\hline & Generalized anxiety disorder & 0.626 & 0.264 & 0.009 & 0.595 & 0.480 & -0.039 \\
\hline & Antisocial personality traits & 0.414 & 0.028 & 0.668 & 0.591 & -0.170 & 0.398 \\
\hline & Psychotic-like experiences & 0.570 & 0.018 & 0.250 & 0.479 & 0.255 & 0.221 \\
\hline & Manic experiences & 0.557 & -0.015 & 0.297 & 0.467 & 0.210 & 0.263 \\
\hline \multirow[t]{5}{*}{ BFI } & Extraversion & -0.021 & -0.541 & 0.279 & -0.313 & -0.233 & 0.463 \\
\hline & Agreeableness & 0.034 & -0.325 & -0.247 & -0.356 & 0.200 & 0.076 \\
\hline & Conscientiousness & -0.113 & -0.349 & -0.235 & -0.460 & 0.077 & 0.070 \\
\hline & Neuroticism & 0.223 & 0.573 & -0.169 & 0.513 & 0.308 & -0.389 \\
\hline & Openness & 0.105 & -0.154 & 0.193 & 0.032 & -0.064 & 0.210 \\
\hline \multirow[t]{5}{*}{ PID-5-NBF } & Negative emotionality & -0.031 & 0.886 & 0.003 & 0.691 & -0.006 & $-\mathbf{0 . 5 3 7}$ \\
\hline & Detachment & -0.100 & 0.720 & 0.017 & 0.523 & -0.073 & -0.443 \\
\hline & Antagonism & -0.129 & 0.391 & 0.562 & 0.500 & -0.502 & 0.026 \\
\hline & Disinhibition & 0.014 & 0.542 & 0.320 & 0.593 & -0.211 & -0.161 \\
\hline & Psychoticism & 0.008 & 0.653 & 0.258 & 0.649 & -0.168 & -0.261 \\
\hline
\end{tabular}

Note: Loadings above V0.1 0.316 are highlighted. Abbreviations: "BFI" = Big Five Inventory; "PID-5-NBF" = Personality Inventory for DSM-5, Norwegian Brief Form. For statistically significant factor correlations, see Figure 1. 
Table 3. Factor score correlations.

\begin{tabular}{|c|c|c|c|c|c|c|}
\hline \multirow[b]{2}{*}{$\begin{array}{l}\text { Correlated-factor } \\
\text { model }\end{array}$} & \multicolumn{3}{|c|}{ Phenotypic } & \multicolumn{3}{|c|}{ Biometric (genetic $\backslash$ environmental) } \\
\hline & Psychopathology & $\begin{array}{l}\text { Personality } \\
\text { pathology }\end{array}$ & Externalizing & Psychopathology & $\begin{array}{c}\text { Personality } \\
\text { pathology } \\
0.28\end{array}$ & $\begin{array}{c}\text { Externalizing } \\
-0.24\end{array}$ \\
\hline Psychopathology & $\begin{array}{c}1 \\
040\end{array}$ & - & - & 1 & $(0.21,0.34)$ & $(-0.31,-0.18)$ \\
\hline Personality pathology & $\begin{array}{c}0.49 \\
(0.46,0.52) \\
-0.17\end{array}$ & $\begin{array}{c}1 \\
0.13\end{array}$ & - & $\begin{array}{c}0.75 \\
(0.67,0.82) \\
-0.08\end{array}$ & 1 & $\begin{array}{c}0.22 \\
(0.15,0.28)\end{array}$ \\
\hline Externalizing & $(-0.20,-0.13)$ & $\begin{array}{c}0.13 \\
(0.09,0.17)\end{array}$ & 1 & $(-0.18,0.03)$ & $(-0.11,0.11)$ & 1 \\
\hline Bi-factor model & Psychopathology & Internalizing & Externalizing & Psychopathology & $\begin{array}{c}\text { Internalizing } \\
-0.20\end{array}$ & $\begin{array}{c}\text { Externalizing } \\
\quad-0.25\end{array}$ \\
\hline Psychopathology & $\begin{array}{c}1 \\
-0.04\end{array}$ & - & - & $\begin{array}{c}1 \\
0.18\end{array}$ & $(-0.26,-0.13)$ & $\begin{array}{c}(-0.31,-0.18) \\
0.14\end{array}$ \\
\hline $\begin{array}{l}\text { Internalizing } \\
\text { Externalizing }\end{array}$ & $\begin{array}{c}(-0.08,-0.01) \\
-0.18 \\
(-0.21,-0.13)\end{array}$ & $\begin{array}{c}1 \\
-0.04 \\
(-0.08,-0.01)\end{array}$ & - & $\begin{array}{c}(0.07,0.31) \\
-0.07 \\
(-0.18,0.04)\end{array}$ & $\begin{array}{c}1 \\
-0.38 \\
(-0.53,-0.25)\end{array}$ & $(0 ., 0.14)$ \\
\hline
\end{tabular}

Note: Phenotypic correlations are Pearson correlations of factor scores, below-diagonal cells under biometric correlations give genetic correlations, and above-diagonal cells give environmental correlations. The correlations are based on model-derived (phenotypic) factor scores and can differ from model-implied latent correlations of Figure 1, e.g., due to measurement noise (van den Berg et al. 2007). 


\section{Figure caption}

Figure 1. Parallel analysis and path diagrams of correlated-and bi-factor models of psychopathology and personality (color figure in online version). a) The number of observed eigenvalues (circles) above parallelanalysis ('zero-correlation') lines indicates the correct number of factors (i.e., 3); the two thin lines give upper (solid line; number of twin pairs) and lower (dashed line; number of twins) bounds for eigenvalues from the parallel analysis (Rosenström et al. 2017). b) Arrows show correlated-factor model loadings above V0.1 (Table 2 for exact numeric values). c) Bi-factor loadings. Solid arrow heads indicate positive loadings and open arrow heads indicate negative loadings. Color codes correspond to bi-factor rotation only for clarity, and " $p$ " refers to a general psychopathology factor. Black arcs indicate statistically significant factor correlations (note: Internalizing and Externalizing factors could have correlated in the oblique bi-factor solution, but they did not). 
Figure

b)

a)
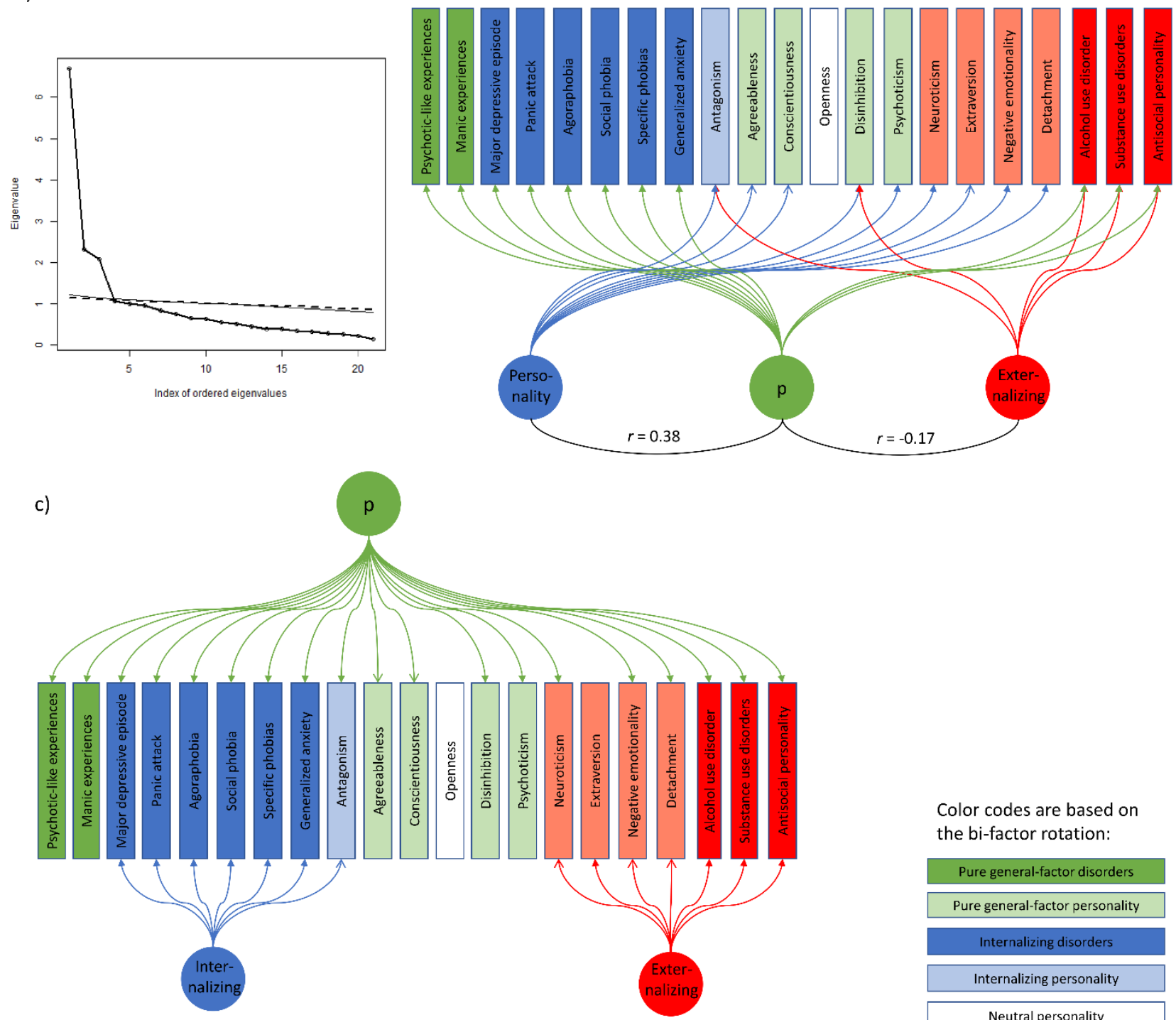

Color codes are based on the bi-factor rotation:

\begin{tabular}{|c|}
\hline \multicolumn{1}{|c|}{ Pure general-factor disorders } \\
\hline Pure general-factor personality \\
\hline Internalizing disorders \\
\hline Internalizing personality \\
\hline Neutral personality \\
\hline Externalizing disorders \\
\hline Externalizing personality \\
\hline
\end{tabular}


SUPPLEMENTARY ONLINE MATERIAL:

\section{Joint factorial structure of psychopathology and personality}

Tom Rosenström ${ }^{1,2, *}$, Line C. Gjerde ${ }^{1,3}$, Robert F. Krueger ${ }^{4}$, Steven H. Aggen ${ }^{5}$, Nikolai Olavi Czajkowski $^{1,3}$, Nathan A. Gillespie ${ }^{5}$, Kenneth S. Kendler ${ }^{5,6,7}$, Ted Reichborn-Kjennerud ${ }^{1,8}$, Fartein Ask Torvik ${ }^{1,3, \dagger}$, Eivind Ystrom ${ }^{1,3,8, \dagger}$

${ }^{1}$ Department of Mental Disorders, Norwegian Institute of Public Health, Oslo, Norway;

${ }^{2}$ Department of Psychology and Logopedics, University of Helsinki, Finland;

${ }^{3}$ Department of Psychology, University of Oslo, Norway;

${ }^{4}$ Department of Psychology, University of Minnesota, USA;

${ }^{5}$ Department of Psychiatry, Virginia Institute for Psychiatric and Behavioral Genetics, Virginia Commonwealth University, Richmond, VA, USA;

${ }^{6}$ Deparment of Human and Molecular Genetics, Virginia Commonwealth University, Richmond, VA, USA;

${ }^{7}$ Department of Psychiatry, Virginia Commonwealth University, Richmond, VA, USA;

${ }^{8}$ Institute of Clinical Medicine, University of Oslo, Norway;

${ }^{8}$ PharmacoEpidemiology and Drug Safety Research Group, School of Pharmacy, University of Oslo, Norway;

*Correspondence to tom.rosenstrom@helsinki.fi;

†Joint senior authors 


\section{Supplementary contents}

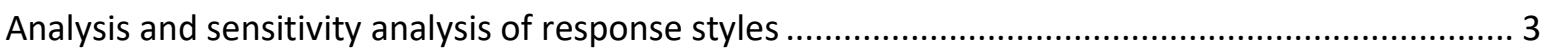

How response style variables were computed? …....................................................................... 3

How the raw averages and correlations looked like? ................................................................... 4

Shortly on parallel analysis method for determining factor number ............................................... 4

Technical supplement to behavior genetic analysis...................................................................... 5

Rotations under multivariate normal and non-normal distributions ............................................. 6 


\section{Analysis and sensitivity analysis of response styles}

When we included raw personality-trait sum scores and psychiatric diagnoses to the same exploratory factor analysis with a bi-factor rotation, we observed similar loading patterns as in the main text (Supplementary Table S1) but with one more specific factor (Figure S1). From this, we also noted that inclusion of PID-5-NBF compulsivity did not alter the overall structure either. We then examined orthogonal-, correlated-, and bi-factor solutions with response styles variables included, and always found one personality factor out of the four factors that overlapped with response style on BFI questionnaire (Supplementary Table S2). Moreover, the response style variables represented the strongest loadings on the factor, whereas psychiatric disorders did not load on it. This suggested that response style in BFI inventory represented a source of confounding for a psychopathology model. In contrast, response style in PID-5-NBF was related to general psychopathology. However, the removal of the BFI response styles did not have major effects on the bi-factor rotated structure of the three first factors.

\section{How response style variables were computed?}

Each of the 44 Big Five Inventory items is a statement directed at aspects of the test taker's normal personality, which he or she responds to using an ordinal-valued, 5-point Likert scale from "strongly disagree" (score 1) to "strongly agree" (score 5). The statements are balanced so that for some statements a high score is associated with a high trait value and for other statements the high score is associated with a low trait value. Then, Extreme Response Style (ERS) is defined as the number of items where the subject endorsed the extreme alternatives (scores 1 and 5), whereas Acquiescent Response Style (ARS) is a sum of weights 1 for "agree", 2 for "strongly agree", and 0 for other endorsements. Analogous variables were computed for the pathological personality traits, assessed 
with four-level ordinal response format. All continuous-valued variables (ERS, ARS, and personality traits) were standardized to mean of zero and variance of one.

\section{How the raw averages and correlations looked like?}

For comprehensiveness, Figure S2 shows all correlations in the data investigated in the main text.

The Table 1 in the main text showed prevalence of the disorders, and although we used standardized personality trait scores, the Supplementary Table S3 complements these information with unstandardized score averages.

\section{Shortly on parallel analysis method for determining factor number}

In this section, we briefly explain our use of Parallel Analysis (PA) method for convenience, although all the content is also available in pertinent literature (Horn 1965; Garrido et al. 2013; Rosenström et al. 2017). The logic of the PA method, as applied here, is the following. Geometrically, the

eigenvalues $\lambda_{1}, \ldots, \lambda_{d}$, of a correlation matrix correspond to dilations or contractions of the underlying $d$-dimensional data cloud to the directions of their corresponding eigenvectors. Because correlation is computed as covariance for standardized variables having variance 1 , any dilation ( $\lambda_{i}>1$ for some $\left.i\right)$ must imply correlations and be balanced by contractions $\left(\lambda_{j}<1\right.$ for some $\left.j \neq i\right)$. If $\lambda_{i}=1$ for all $i$, the data is uncorrelated. For each $\lambda_{i}>1$, there must be a corresponding dimension of linear dependence (correlations). Thus, in an infinitely large sample, modeling fewer underlying factors for the data than the number of eigenvalues exceeding 1 , would directly imply unmodeled correlations. In a finite sample, however, sampling variance induces some chance correlations even when uncorrelated processes generate the data, and the PA simulation characterizes how much on average for a given sample size. Thus, in our case, modeling fewer factors than there are (ordered) data-derived 
eigenvalues exceeding the corresponding PA values, would imply that the associated 'comorbidity model' misses some comorbidity. Modeling more factors would instead imply that sampling variance ('noise') is being interpreted. Thus, only one sensible number of factors exists.

While this is the essential logic, please see Garrido et al. (2013) for treatment of ordinalvalued data and Rosenström et al. (2017) for assessing sensitivity to within-twin-pair correlations with upper and lower bounds. Briefly, within-twin-pair correlations reduce the amount of independent information in the available observations, thus reducing the effective sample size. But whatever the correlation, the effective sample size will be between the number of unique twin pairs and the number of unique twins in the data. If both the sample sizes deliver the same conclusion in PA, then it holds for intermediate correlations as well. This frequently occurs in samples as large as herein. While it is not immediately obvious how the ordinal-valued data should be handled, extensive simulations of Garrido et al. (2013) suggested that one should compute the real-data eigenvalues from a polychoric correlation matrix.

\section{Technical supplement to behavior genetic analysis}

The twin ACE model of behavior genetics was used to partition the variance-covariance matrix of estimated factor scores into distinct contributions from additive genetic (A) sources of variance, common/shared environmental (C) sources that tend to make twins similar, and non-shared environmental (E) sources of variance that tend to make twins dissimilar, using a priori knowledge that monozygotic twins share $100 \%$ of their segregating genes and dizygotic twins on average $50 \%$ (Neale \& Cardon 1992). In ordinary cross-sectional data one has degrees of freedom for distinguishing only single covariance matrix, but in twin analyses, there are extra degrees of freedom from both dizygotic and monozygotic cross-twin covariances; altogether, a three-fold number of degrees of freedom. A multigroup structural equation model for monozygotic (one group) and 
dizygotic (the other group) twins can be identified and estimated, such that respective within- and cross-twin covariance structures are

$$
\left(\begin{array}{cc}
A+C+E & A+C \\
A+C & A+C+E
\end{array}\right) \text { and }\left(\begin{array}{cc}
A+C+E & \frac{1}{2} A+C \\
\frac{1}{2} A+C & A+C+E
\end{array}\right)
$$

where $A, C$, and $E$ are freely estimable within- and cross-trait variance-covariance matrices for genetic influences, shared environmental influences, and non-shared environmental influences, respectively.

\section{Rotations under multivariate normal and non-normal distributions}

From a narrow technical viewpoint, the correlated-factor and the bi-factor rotation are just different 'faces' of the same symmetric three-dimensional object, a latent population distribution. However, the latent distribution of factor models (a multivariate normal distribution) is typically chosen to facilitate computation, not because it necessarily best reflects 'the nature' (Lei \& Lomax 2005). It can be shown that all rotations produce equivalent fits for multivariate normal distribution and only for that distribution (Hyvärinen et al. 2001). If all but one of the latent dimensions have non-normal distributions, a uniquely interpretable rotation exists. For an analogy, if three microphones are recording simultaneous speech of three individuals in a room, only one 'rotation' of the received speech signals retrieves the three original non-mixed speeches (up to permutation of individuals) (Hyvärinen et al. 2001). While present computation (or those generally seen in psychology and psychiatry) cannot identify such a unique rotation, one that best advances science may nevertheless exist. We and others have put forth practical and logical arguments in favor of the bi-factor rotation, and perhaps future works will increasingly develop technical arguments to support or refute those. 
Supplementary Table S1. Exploratory bi-factor model without regressing out the response styles

\begin{tabular}{|c|c|c|c|c|c|}
\hline \multirow[b]{2}{*}{ Data type } & \multirow[b]{2}{*}{ Variable } & \multicolumn{4}{|c|}{ Bi-factor rotation } \\
\hline & & $\begin{array}{l}\text { General factor: } \\
\text { "Psychopathology" }\end{array}$ & $\begin{array}{c}\text { Specific factor } \\
\# 1: \\
\text { “Internalizing” }\end{array}$ & $\begin{array}{c}\text { Specific factor } \\
\# 2: \\
\text { “Externalizing” }\end{array}$ & $\begin{array}{c}\text { Specific factor } \\
\text { \#3: } \\
\text { "Personality" }\end{array}$ \\
\hline \multirow[t]{11}{*}{ Interview } & Alcohol use disorder & 0.506 & -0.052 & 0.397 & -0.043 \\
\hline & Substance use disorders & 0.539 & 0.082 & 0.519 & -0.025 \\
\hline & Major depressive episode & 0.502 & 0.451 & 0.041 & 0.031 \\
\hline & Panick attack & 0.576 & 0.54 & 0.087 & -0.005 \\
\hline & Agoraphobia & 0.612 & 0.668 & 0.026 & 0.006 \\
\hline & Social phobia & 0.655 & 0.495 & -0.04 & -0.101 \\
\hline & Specific phobias & 0.378 & 0.436 & -0.031 & 0.08 \\
\hline & Generalized anxiety disorder & 0.629 & 0.446 & -0.009 & -0.038 \\
\hline & Antisocial personality traits & 0.539 & -0.194 & 0.485 & 0.002 \\
\hline & Psychotic-like experiences & 0.459 & 0.262 & 0.232 & 0.012 \\
\hline & Manic experiences & 0.44 & 0.228 & 0.273 & 0.025 \\
\hline \multirow[t]{5}{*}{$\mathrm{BFI}$} & Extraversion & -0.412 & -0.012 & 0.517 & 0.34 \\
\hline & Agreeableness & -0.427 & 0.295 & 0.095 & 0.124 \\
\hline & Conscientiousness & -0.573 & 0.307 & -0.031 & 0.337 \\
\hline & Neuroticism & 0.64 & 0.172 & -0.306 & -0.119 \\
\hline & Openness & 0.067 & 0.054 & 0.299 & 0.198 \\
\hline \multirow[t]{6}{*}{ PID-5-NBF } & Negative emotionality & 0.72 & 0.000 & -0.416 & 0.221 \\
\hline & Detachment & 0.563 & -0.136 & -0.406 & 0.052 \\
\hline & Antagonism & 0.441 & -0.359 & 0.088 & 0.38 \\
\hline & Disinhibition & 0.609 & -0.214 & -0.007 & 0.142 \\
\hline & Compulsivity & 0.424 & 0.036 & -0.253 & 0.449 \\
\hline & Psychoticism & 0.637 & -0.079 & -0.144 & 0.372 \\
\hline
\end{tabular}

Note: Loadings above V0.1 are highlighted; "BFI" = Big Five Inventory; "PID-5-NBF" = Personality Inventory for DSM-5, Norwegian Brief Form

Supplementary Table S2. Various exploratory factor analysis rotations with response style (RS) variables included (a large table on the next page). 


\begin{tabular}{|c|c|c|c|c|c|c|c|c|c|c|c|c|c|}
\hline \multirow[b]{2}{*}{ Data type } & \multirow[b]{2}{*}{ Variable } & \multirow[b]{2}{*}{ F1 } & \multirow[b]{2}{*}{ F2/RS } & \multicolumn{3}{|c|}{ Varimax } & \multicolumn{4}{|c|}{ Promax } & \multicolumn{3}{|r|}{ Bi-factor } \\
\hline & & & & F3 & F4 & F1 & F2/RS & F3 & F4 & int & p & ext & RS \\
\hline \multirow[t]{11}{*}{ Interview } & Alcohol use disorder & 0.572 & -0.05 & 0.247 & 0.13 & 0.601 & -0.093 & 0.121 & -0.058 & 0.061 & 0.471 & 0.426 & -0.074 \\
\hline & Substance use disorders & 0.636 & 0.057 & 0.369 & 0.064 & 0.667 & 0.005 & 0.263 & -0.154 & 0.179 & 0.49 & 0.515 & 0.022 \\
\hline & Major depressive episode & 0.14 & 0.031 & 0.637 & 0.151 & 0.071 & 0.077 & 0.636 & 0.031 & 0.505 & 0.432 & 0.032 & 0.053 \\
\hline & Panick attack & 0.182 & 0.02 & 0.759 & 0.128 & 0.11 & 0.061 & 0.766 & -0.032 & 0.615 & 0.482 & 0.077 & 0.039 \\
\hline & Agoraphobia & 0.116 & 0.036 & 0.88 & 0.136 & 0.022 & 0.095 & 0.911 & -0.023 & 0.739 & 0.504 & 0.014 & 0.064 \\
\hline & Social phobia & 0.125 & -0.079 & 0.793 & 0.201 & 0.035 & -0.019 & 0.794 & 0.044 & 0.638 & 0.533 & -0.012 & -0.046 \\
\hline & Specific phobias & 0.044 & 0.014 & 0.535 & 0.126 & -0.022 & 0.062 & 0.549 & 0.043 & 0.441 & 0.328 & -0.037 & 0.038 \\
\hline & Generalized anxiety disorder & 0.162 & -0.027 & 0.73 & 0.209 & 0.08 & 0.029 & 0.717 & 0.065 & 0.567 & 0.529 & 0.019 & 0.002 \\
\hline & Antisocial personality traits & 0.681 & 0.001 & 0.147 & 0.195 & 0.723 & -0.046 & -0.025 & 0.017 & -0.077 & 0.531 & 0.491 & -0.026 \\
\hline & Psychotic-like experiences & 0.327 & 0.009 & 0.459 & 0.092 & 0.308 & 0.007 & 0.416 & -0.062 & 0.32 & 0.405 & 0.229 & 0.005 \\
\hline & Manic experiences & 0.365 & -0.001 & 0.415 & 0.071 & 0.359 & -0.015 & 0.365 & -0.091 & 0.278 & 0.39 & 0.273 & -0.012 \\
\hline \multirow[t]{7}{*}{$\mathrm{BFI}$} & Extraversion & 0.23 & 0.514 & -0.322 & -0.3 & 0.32 & 0.435 & -0.307 & -0.258 & -0.262 & -0.29 & 0.37 & 0.449 \\
\hline & Agreeableness & -0.271 & 0.483 & -0.008 & -0.302 & -0.274 & 0.487 & 0.139 & -0.186 & 0.138 & -0.402 & -0.073 & 0.465 \\
\hline & Conscientiousness & -0.348 & 0.447 & -0.157 & -0.278 & -0.348 & 0.457 & -0.016 & -0.117 & 0.01 & -0.475 & -0.15 & 0.435 \\
\hline & Neuroticism & 0.027 & -0.294 & 0.527 & 0.4 & -0.071 & -0.207 & 0.464 & 0.312 & 0.355 & 0.555 & -0.196 & -0.233 \\
\hline & Openness & 0.303 & 0.359 & 0.05 & 0.001 & 0.326 & 0.341 & 0.007 & -0.02 & -0.03 & 0.137 & 0.269 & 0.334 \\
\hline & Extreme response style in $\mathrm{BFI}$ & -0.126 & 0.887 & 0.024 & 0.008 & -0.167 & 0.959 & 0.084 & 0.214 & 0.022 & -0.105 & -0.096 & 0.894 \\
\hline & Acquiescent response style in BFI & 0.14 & 0.802 & 0.122 & 0.079 & 0.114 & 0.852 & 0.117 & 0.191 & 0.033 & 0.12 & 0.095 & 0.8 \\
\hline \multirow[t]{8}{*}{ PID-5-NBF } & Negative emotionality & -0.023 & -0.124 & 0.363 & 0.795 & -0.17 & 0.051 & 0.203 & 0.855 & 0.08 & 0.766 & -0.432 & -0.015 \\
\hline & Detachment & -0.049 & -0.254 & 0.199 & 0.649 & -0.159 & -0.121 & 0.059 & 0.694 & -0.013 & 0.584 & -0.38 & -0.164 \\
\hline & Antagonism & 0.4 & 0.016 & -0.148 & 0.564 & 0.385 & 0.068 & -0.382 & 0.586 & -0.41 & 0.573 & 0.067 & 0.05 \\
\hline & Disinhibition & 0.319 & -0.048 & 0.137 & 0.598 & 0.263 & 0.033 & -0.064 & 0.584 & -0.139 & 0.678 & -0.028 & 0.004 \\
\hline & Compulsivity & 0.014 & 0.039 & 0.148 & 0.606 & -0.085 & 0.169 & 0.012 & 0.692 & -0.069 & 0.54 & -0.296 & 0.117 \\
\hline & Psychoticism & 0.207 & 0.024 & 0.206 & 0.711 & 0.112 & 0.151 & 0.01 & 0.75 & -0.091 & 0.737 & -0.183 & 0.101 \\
\hline & Extreme response style in PID5 & -0.237 & 0.195 & -0.186 & -0.749 & -0.148 & 0.078 & 0.036 & -0.747 & 0.122 & -0.787 & 0.18 & 0.116 \\
\hline & Acquiescent response style in PID5 & 0.067 & 0.008 & 0.223 & 0.906 & -0.074 & 0.193 & 0.008 & 1.012 & -0.108 & 0.833 & -0.404 & 0.12 \\
\hline
\end{tabular}


Supplementary Table S3. Unstandarized mean scores for the personality traits, plus their standard errors (SD), and numbers of observations they were based on

\begin{tabular}{rccc}
\hline Variable & $\boldsymbol{n}_{\text {available }}$ & Mean & SD \\
Extraversion (range 1-5) & 2295 & 3.50 & 0.64 \\
Agreeableness (range 1-5) & 2293 & 3.94 & 0.42 \\
Conscientiousness (range 1-5) & 2295 & 3.87 & 0.47 \\
Neuroticism (range 1-5) & 2295 & 2.50 & 0.67 \\
Openness (range 1-5) & 2291 & 3.32 & 0.55 \\
Negative emotionality (range 1-4) & 2294 & 1.32 & 0.42 \\
Detachment (range 1-4) & 2295 & 1.54 & 0.54 \\
Antagonism (range 1-4) & 2296 & 1.23 & 0.31 \\
Disinhibition (range 1-4) & 2296 & 1.57 & 0.49 \\
Compulsivity (range 1-4) & 2295 & 1.40 & 0.52 \\
Psychoticism (range 1-4) & 2293 & 1.27 & 0.43 \\
\hline
\end{tabular}




\section{Supplementary Figures}
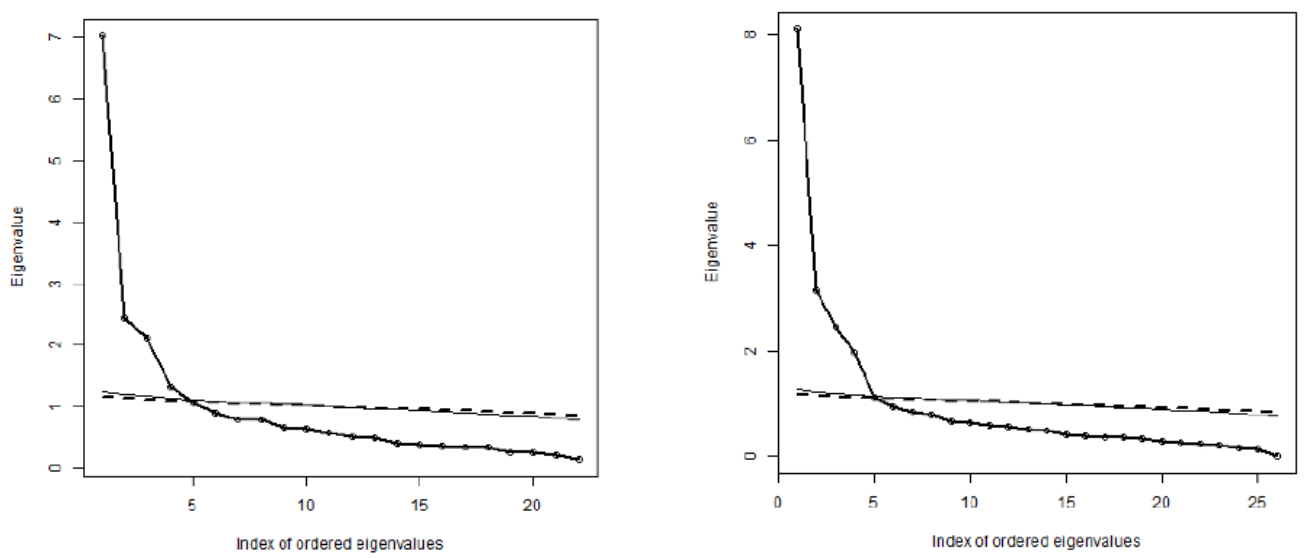

Figure S1. Parallel analysis results without (left) and with (right) response style variables. Number of observed eigenvalues (circles) above parallel-analysis ('zero-correlation') lines indicates the correct number of factors (i.e., 4 in both cases). Note response styles were not regressed out, but left out, in the analysis of left panel. Thus, they were implicitly present. 


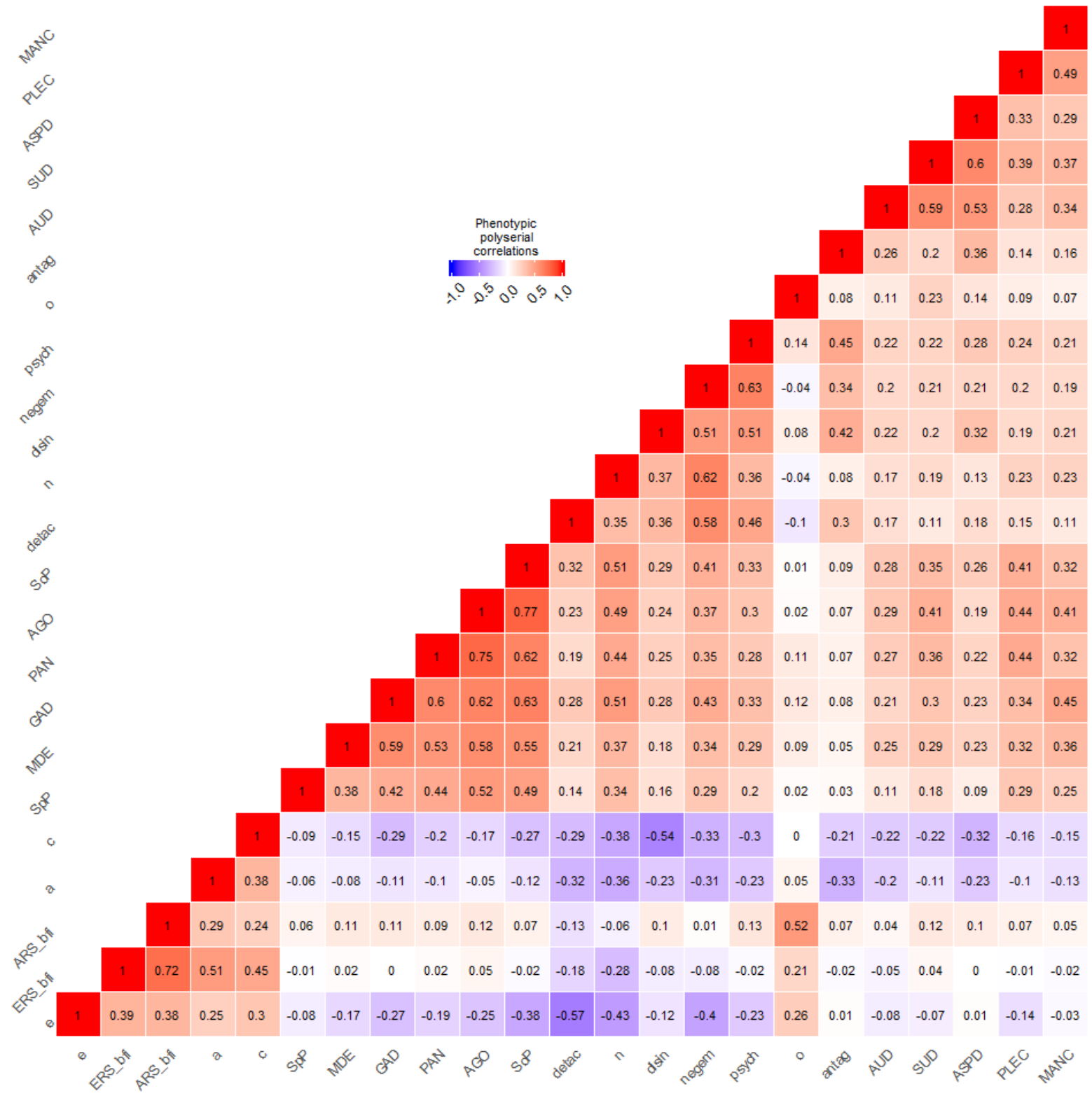

Figure S2. Phenotypic correlations under liability-threshold modelling for ordinal data. Abbreviations: "e" = Extraversion in Big Five Inventory (BFI); "ERS_bfi" = Extreme Response Style in BFI; "ARS_bfi" = Acquiescent Response Style in BFI; "a" = Agreeableness in $\mathrm{BFI}$; " $\mathrm{C}$ " = Conscientiousness in BFI; "SpP" = Specific Phobias; "MDE" = Major Depressive Episode; "GAD" = Generalized Anxiety Disorder; "PAN" = Panick attack; "AGO" = Agoraphobia; "SoP" = Social Phobia; "detach" = Detachment in Personality Inventory for DSM-5, Norwegian Brief Form (PID-5-NBF); " $n$ " = Neuroticism in BFI; "disin" = Disinhibition in PID-5-NBF; "negem" = Negative emotionality in PID-5-NBF; "psych" = Psychoticism in PID-5-NBF; "o" = Openness to experience in BFI; "antag" = Antagonism in PID5-NBF; "AUD" = Alcohol Use Disorder or Dependency; "SUD" = Substance Use Disorder; "ASPD" = Antisocial personality disorder traits; "PLEC" = Psychotic-like experiences, categorical score; "MANC" = Manic experiences, categorical score. 